the mercy of the breeze, although some observations seemed to indicate a limited control of the thread by manipulation.

He added that on previous occasions he had actually observed the laying in, by air currents, of lines which were immediately used for foundations. The above studies had been undertaken simply to verify such studies, and because he had retained but the briefest notes of former observations. While this use of air currents is certainly placed beyond doubt, it is as certainly not the only mode of laying foundation lines, and is dependent very much upon the site chosen, the condition of the wind, the abundance of prey, etc. Webs built in large open spaces are perhaps always laid out by bridge-lines. In more contracted sites, the frame-lines are generally carried around, and often a fousdation is the result of both methods. ${ }^{1}$

\title{
OCTOBER 11.
}

The President, Dr. Ruschenberger, in the chair.

Three hundred and sixty-four persons present.

On the Nature of the Diphtheritic Contagium.-Dr. H. C. WOoD stated that the researches which formed the basis of his remarks had been made under the auspices; and, indeed, at the suggestion of the National Board of Health, by Dr. Henry F. Formad and himself, who were jointly responsible for the facts and inductions and jointly deserving of whatever reprobation or approbation might be due. The full text of the work is now in the hands of the National Board, and will be shortly published by them.

In the spring of 1880 work was begun by inoculating rabbits with diptheritic membrane taken from the throats of patients at Philadelphia. It was found that only in a very few cases was anything like diphtheria produced in the rabbit by inoculating with the membrane. The inoculations were practiced by putting pieces of the material sometimes under the skin, sometimes deep in the muscles. Many rabbits died after some weeks, not of diphtheria, but of tuberculosis. In a series of experiments it was shown that this tuberculosis was an indirect and not a direct result of the inoculation, and that any apparent relation between the two diseases is only apparent, not real. Next, the tracheas of a series of rabbits were opened and false membrane inserted. It

${ }^{1}$ Since these notes were communicated, a copy of Nature (Sept. 22, 1881) has been received, in which it is said that Mr. Cambridge in the second volume of his Spiders of Dorset modifies the opinion above quoted concerning the influence of air currents. I have not yet received that volume but make this statement on the authority of the journal referred to.H. C. McC. 
was found that under these circumstances a severe trachitis was frequently produced, and was attended by an abundant formation of pseudo-membrane. Careful studies made of the false membrane of diphtheria and of this false membrane showed that the two were identical, both containing in abundance fibrin fibres, corpuseular elements, and various forms of micrococei. To determine whether other inflammations of the trachea than that caused by diphtheria or its membrane are accompanied by the formation of false membrane, a number of experiments were made, and it was demonstrated that the production of false membrane has nothing specific in it, but that any trachitis of sufficient severity is accompanied by this product. Careful studies also showed that this false membrane does not differ in its constitution from that of true diphtheria, except it be that the micrococci are not so abundant in it. They always found some micrococci, and in some of these traumatic pseudo-membranes they were almost as numerous as in the diphtheritic exudation.

Last spring they resumed their investigations. Having heard that there was a very severe epidemic in Ludington, Michigan, Dr. Formad was despatched to examine cases and collect material. He found a small town situated upon the shore of Lake Michigan, in the centre of the lumber region, with inhabitants mostly engaged in the lumber trade and in managing very numerous large saw-mills. The town was all built upon high ground except the Third Ward. This occupied a low swamp which had been filled in largely with sawdust. The soil was so moist that a hole dug in it would fill at once with water, and but few houses had any attempts at cellars. It was in this district that the disease had prevailed. Almost all the children had had it, and one-third of them were said to have died. Dr. Formad examined a large number of cases, obtained a supply of diphtheritic membrane and brought home pieces of the internal organ of a child upon whom he had made an autopsy. In every case the blood was found more or less full of micrococci, some free, others in zooglox masses, others in the white blood-corpuscles. The organs brought home also all contained micrococci, which were especially abundant in the kidneys, where they formed numerous thrombi, choking up and distending the blood vessels. In the summer of 1880 they examined the blood of several cases of endemic Philadelphia diphtheria, and in no case found any new elements in it. But during the present summer they had found micrococei in the blood of Philadelphia diphtheritic patients, showing that the differences in the diseases are simply in degree, not in kind.

Experiments were now made with the Ludington material upon animals. Inoculations were practiced under the skin, deep in the muscles, and in the trachea. In all cases the result was similar. A grayish exudation appeared at the seat of inoculation, along with much local inflammation, the animal sickened, and in 
the course of a few days death occurred. The local symptoms increased and widened. In some cases the false membrane spread from where the poison had been put in the trachea up to the mouth. The blood examined during life or after death was found to contain micrococcs precisely similar to those found in the Ludington cases, and in a few instances micrococci were found in abundance in the internal organs. Studies made upon the blood of these animals, as well as upon the Ludington cases, show that the micrococci first attack the white blood-corpuscles, in which they move with a vibratile motion. Under their influence the corpuscles alter their appearances, losing their granulations. They finally become full of the microcacci, which now are quiescent and increase until the corpuscle bursts and the contents escape as an irregular, transparent mass full of micrococci, and form the so-called zoogloæ masses. In the diphtheritic membrane the micrococci exists frequently in balls, and it is plain that these collections are merely leucocytes full of the plant. The bonemarrow of the animal was found full of leucocytes and cells containing micrococci.

The question now arose, is the disease produced by diphtheritic inoculation in the rabbit diphtheria? They concluded that it is, because the poison producing it is the same, the symptoms manifested during life are the same, and the post-mortem lesions are identical. The contagious character of the disease is retained, as they succeeded in passing it from rabbit to rabbit.

Their next series of experiments were directed to determine whether the micrococci are or are not the cause of the affection. The experiments of Curtis and Satterthwaite, of New York, have shown that the infectious character of diphtheria depends upon its solid particles; for when an infusion of the membrane was filtered, it became less and less toxic in proportion as the filtration was more and more perfect; and when the infusion was filtere? through clay, the filtrate was harmless.

The urine of patients suffering from malignant diphtheria is full of micrococci, and may contain no other solid material. Following the experiments of Letzerich, they filtered this urine and then dried the filter-paper. Upon experimenting they found this even more deadly in its effects than is the membrane. The symptoms and lesions following in the rabbit inoculation with such paper are precisely those which would have ensued had a piece of diphtheritic kidney or membrane been employed. This experiment shows that the solid particles of the membrane, which are the essential poison of malignant diphtheria, are the micrococci, which must be either the poison itself or the carriers or producers of the poison.

Culture-Experiments were performed in the manner commended by Klein and that recommended by Sternberg. The first method seemed the best for the purpose of studying the develop- 
ment of the micrococcus itself; the second, the best for the obtaining of it in quantity for experimentation.

Micrococci were cultivated from the surface of ordinary sore throats, from furred tongue, from cases of mild diphtheria as commonly seen in Philadelphia, and from Ludington cases. There were no differences to be detected in the general or special appearance of the various micrococci, and no constant differences in size. They all formed similar shapes in the culture-apparatus ; they had this difference, however,-whilst the Ludington micrococci grew most rapidly and eagerly, generation after generation up to the tenth, those from Philadelphia diphtheria ceased their growth in the fourth or fifth generation, whilst those taken from furred tongue, never got beyond the third transplantation. Various culture-fluids were used, but the results were identical. They concluded, therefore, that as no difference is detectable between the micrococci found in ordinary sore throat and those of diphtheria, save only in their reproductive activity, they are the same organisms in different states. As the result of some hundreds of cultures, they believe that the vitality under artificial culture is in direct proportion to the malignancy of the case from which the plant has been taken.

They next made a series of experiments of inoculating rabbits with cultivated micrococci, and succeeded in producing diphtheria with the second generation, but never with any later product. This success, taken in conjunction with the urine experiments already spoken of, seemed sufficient to establish the fact that the micrococci are the fons et origo mali of diphtheria. The experiments of Pasteur and others have proven that it is possible for an inert organism to be changed into one possessed of most virulent activity, or vice versa, and it was believed that direct proof could be offered that the micrococci of the mouth are really identical in species with the micrococci of diphtheria, and do not merely seem to be so. The Ludington membrane was exposed for some weeks to the air in a dried condition. There was no putridity or other change detectable in it; but, whereas formerly it had been most virulent, now it was inert, and its micrococci not only looked like those taken from an ordinary angina, but acted like them. They were not dead, they had still power of multiplication, but they no longer grew in the culture-fluid beyond the third or fourth generation. Certainly they were specifically the same as they had been, and certainly, therefore, the power of rapid growth in culture-fluids and in the body of the rabbit is not a specific character of the diphtheria Micrococcus.

As is well known, Pasteur attributes the change from an active to an inert organism to the influence of the oxygen of the air upon the organism. Whether this be true of the diphtheria Micrococcus is uncertain, but the effects of exposure of the dried membrane seem to point in such direction. 
With the facts that are known in regard to the clinical history of diphtheria and those which they had determined in their research, it is easy to make out a theory of the disease which reconciles all existing differences of opinion and seems to be true.

A child gets a catarrhal anoina or trachitis. Under the stimulation of the inflammation products the inert micrococei in the mouth begin to grow; and, if the conditions be farorable, the sluggish plant may be finally transformed into an active organism, and a self-generated diphtheria results. It is plain that if this be correct there must be everv grade of case between one which is fatal and one which is checked before it fairly passes the bounds of an ordinary sore throat. Every practitioner knows that such diversity does exist, Again, conditions outside of the body favoring the passage of inert into active micrococci may exist, and the air at last become well loaded with organisms, which, alighting upon the tender throats of children. may begin to grow and themselves produce violent angina, trachitis, and finally fatal diphtheria.

In the first instance we have endemic diphtheria as we see it in Philadelphia; in the second, the malignant epidemic form of the disease as it existed in Ludington. It is also apparent that in the endemic cases the plant whose activity has been developed within the patient may escape with the breath, and a second case of diphtheria be produced by contagion. It is also plain that as the plant gradually in such a case passes from the inert to the active state, there must be degrees of activity in the contagium, one case being more apt to give the disease than is another; also that the malignant diphtheria must be more contagious than the mild endemic cases.

\section{October 18.}

The President, Dr. Ruschenberger, in the chair.

\section{Twenty-seven persons present.}

A paper entitled "Revision of the Tertiary Species of Arca of the Eastern and Southern United States," by Angelo Heilprin, was presented for publication.

The death of Dr. Benj. H. Coates, a member, was announced.

Notes on Mistletoes.-Mr. Thomas Meenan called attention to some fine specimens on the table of Phoradendron juniperum, var. Libocedri Engelmann, and Arceuthobium occidentale var. abietinum Engelmann, from Washoe Valley, Nevada, contributed by Mrs. Ross Lewers of Franktown and said it might be worth noting a few facts in relation to Mistletoes, which, though perhaps 


\section{$2 \mathrm{BHL}$ Biodiversity Heritage Library}

Wood, H. C. 1881. "On the Nature of the Diphtheritic Contagium." Proceedings of the Academy of Natural Sciences of Philadelphia 33, 435-439.

View This Item Online: https://www.biodiversitylibrary.org/item/30732

Permalink: https://www.biodiversitylibrary.org/partpdf/85298

\section{Holding Institution}

MBLWHOI Library

\section{Sponsored by}

MBLWHOI Library

\section{Copyright \& Reuse}

Copyright Status: NOT_IN_COPYRIGHT

This document was created from content at the Biodiversity Heritage Library, the world's largest open access digital library for biodiversity literature and archives. Visit BHL at https://www.biodiversitylibrary.org. 